\title{
Understanding the seismic response of geosynthetic reinforced slope
}

\author{
Sao-Jeng Chao ${ }^{\text {i) }}$, Han-Sheng Liu ${ }^{\text {ii) }}$ and Chien-Hua Kao ${ }^{\text {ii) }}$ \\ i) Professor, Department of Civil Engineering, National Ilan University, 1, Sec. 1, Shen-Lung Road, Ilan, 260, Taiwan. \\ ii) Graduate Student, Department of Civil Engineering, National Ilan University, 1, Sec. 1, Shen-Lung Road, Ilan, 260, Taiwan.
}

\begin{abstract}
Geosynthetic reinforced slopes perform reasonably well under earthquake loading conditions as we already know. Consequently, the seismic response of the geosynthetic reinforced slope is worthy to be explored in detail. This study sets earthquake monitoring system for the geosynthetic reinforced slope built in FoGuang University, Ilan, Taiwan. There are totally 3 seismic instruments arranged to record the acceleration time histories of the ground surface, the middle portion and the top portion of the geosynthetic reinforced slope. The recorded acceleration data can be used to understand the seismic response of geosynthetic reinforced slope straightforwardly. The amplification factor for the geosynthetic reinforced slope is discussed in this paper using the recorded data. In addition, this study also simulates the seismic response of geosynthetic reinforced slope, using the acceleration time history recorded at the ground surface from the site, utilizing the finite element computer program PLAXIS. Finally, the predicted results obtained from PLAXIS finite element program are compared with the records from the seismic monitoring system. The agreeable comparison results give us the confidence to explore the seismic response of geosynthetic reinforced slopes by means of numerical technique.
\end{abstract}

Keywords: seismic response, geosynthetic reinforced slope, seismic instrument, finite element method.

\section{INTRODUCTION}

The concept of reinforced soil has been put forward and its application has existed in the ancient China quite long time ago (Chao, 2010a). As a matter of fact, with the engineering technology advancing and the progressive development of the reinforcing materials, the application of geosynthetic reinforced slope plays important role in geotechnical practice worldwide.

Specifically speaking, geosynthetic reinforced slopes have gradually replaced the traditional slope retaining facilities and hence progressively become the mainstream design in the United States, Japan, Europe, and other countries. The main reasons are summarized as followed: low construction expense, short construction period, reaching the purpose of earthwork balance, withstanding large deformation, environment friendly, landscaping appearance, and the flexible feature for seismic effect.

In addition, the geosynthetic reinforced slopes with porosity and permeability are perfectly suitable for the use of ecological engineering design, more to the point the application in the frequent earthquakes and natural disasters in Taiwan. Therefore, geosysthetic reinforced slopes were introduced into Taiwan around late 1980s. Since then, the extremely cost-effective geosynthetic reinforced slopes have been built more and more in Taiwan.
With the aim of understanding the seismic response of geosynthetic reinforced slope comprehensively, three seismic instruments, named Palert ( $\mathrm{Wu}, 2008)$, have been set up in the field to observe the acceleration time histories of the ground surface, the middle portion and the top portion of the geosynthetic reinforced slope built in the FoGuang University, Ilan, Taiwan. After accomplishing the monitoring process, the in-situ recorded results can then be used to acquaint with the site amplification effect for the seismic response of geosynthetic reinforced slope.

As a final point, for the purpose of predicting the seismic behaviors of the geosynthetic reinforced slopes during the earthquake, the PLAXIS finite element computer program is utilized to investigate the seismic response of the study geosynthetic reinforced slope. It is expected to provide more detail information for geotechnical engineers during the design phase from the outcome of this work.

\section{STUDY SITE DESCRIPTION}

The project site (Campus of FoGuang University) is located in southeast piedmont of Chonan Mountain in Choshi, Ilan, Taiwan (Chao et al., 2010b). The study geosynthetic reinforced slope is designed with the arrangement of three tiers. The first tier (base tier) is $2.5 \mathrm{~m}$ in height with a level platform, which is $4 \sim 8 \mathrm{~m}$ in 
width; the second tier (intermediate tier) with reinforced slope design angle as $45^{\circ}$ and vertical elevation of $15.5 \mathrm{~m}$; the third tier (top tier) with reinforced slope design angle as $73^{\circ}$ and vertical elevation of $12.5 \mathrm{~m}$. Moreover, a thin backfill for the purpose of vegetation of a $2 \mathrm{~m}$ thick soil with a rather gentle slope is placed on the top of the third tier.

The geosynthetic reinforced slope design for the FoGuang University is chosen as the material specifications for $200 \mathrm{kN} / \mathrm{m} \times 4 \mathrm{~m} \times 100 \mathrm{~m}$, which is equal to a long-term allowable strength of $50 \mathrm{kN} / \mathrm{m}$. The material type of the geosynthetic reinforcement is polymer-fiber and the failure extension strain is required to be less than $15 \%$ corresponding to the ultimate reinforcement tensile strength.

In this monitoring site of the geosynthetic reinforced slope, there are totally 3 Palert earthquake seismic sensing devices set up in the field and a host personal computer is used to record the acceleration time histories of the well arranged instruments of the seismic monitoring system. It is anticipated that the 3 Palert seismic sensing instruments, which are directly mounted on the base, the middle portion and the upper portion of the geosynthetic reinforced slope, can precisely monitor and record the earthquake responses, especially for the seismic acceleration time histories of the geosynthetic reinforced slope.

\section{IN-SITU MONITORED DATA OF THE GEOSYNTHETIC REINFORCED SLOPE}

Taiwan is a gorgeous island located in conjunction area of the Eurasian Plate and the Philippine Plate but also is a hazardous area of seismic activity intense on the other hand. The annual average number about 18,500 earthquakes occurred while about 1,000 times as strong ground motions in Taiwan.

The seismic monitoring system in this study is to document the observation acceleration records at the first tier (base tier), the second tier (intermediate tier), and the third tier (top tier) of the geosynthetic reinforced slope. It is achieved by using the seismic sensing devices and recording the seismic data at the host personal computer. The recorded seismic data can then be used to demonstrate the three axial acceleration, velocity and displacement data of the instrumented geosynthetic reinforced slope.

In this study, the seismic monitoring system has being enabled to work since late October, 2013. However, it was required to reset the recording processes due to the computer failure damage several times, thus only about dozens of seismic data have been recorded to date. There are totally 11 recorded seismic data collected from all the sensing instruments. In Figures 1 to 3 , we merely demonstrate 3 orthogonal components of acceleration time histories at different elevations of the geosynthetic reinforced slope recorded on February 22, 2014 earthquake.

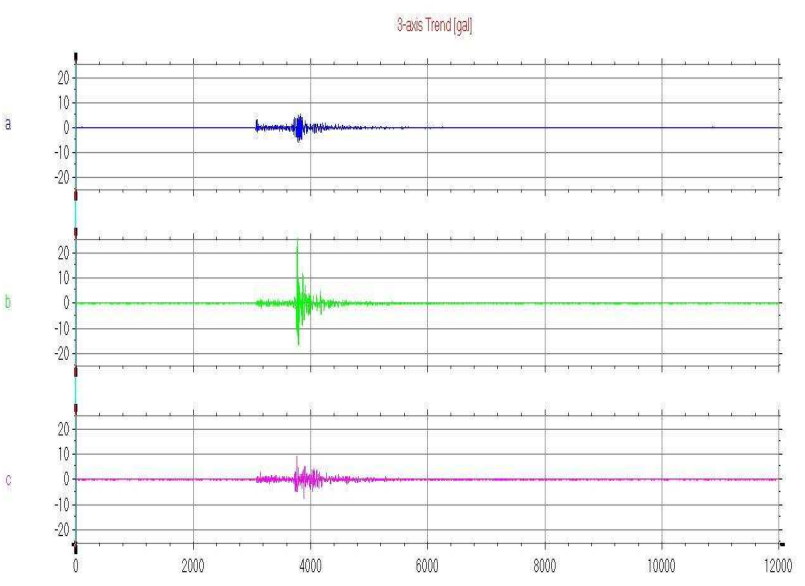

Fig. 1. Acceleration time histories recorded at top portion of the geosynthetic reinforced slope (2014/02/22).

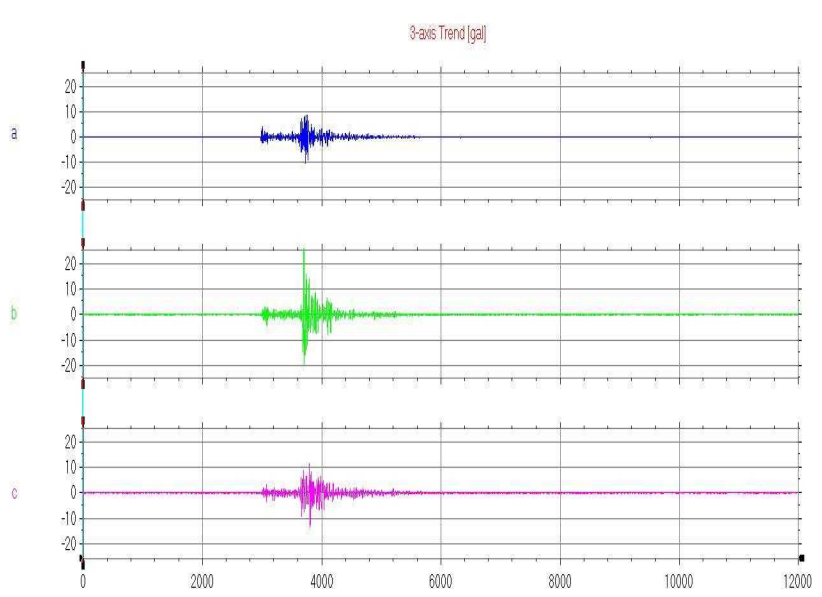

Fig. 2. Acceleration time histories recorded at middle portion of the geosynthetic reinforced slope (2014/02/22).

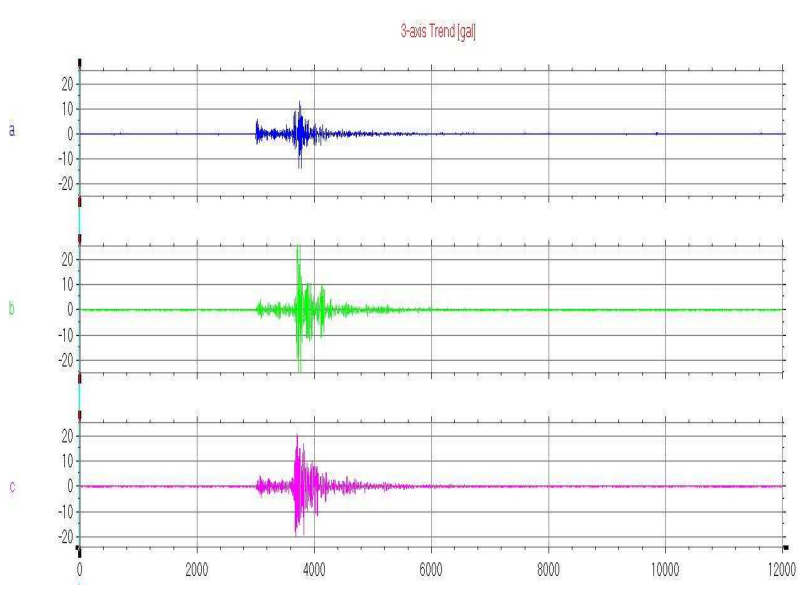

Fig. 3. Acceleration time histories recorded at ground surface of the geosynthetic reinforced slope (2014/02/22).

The 3 seismic sensing devices Palert were arranged at the first tier (base tier), the second tier (intermediate tier), and the third tier (top tier) of geosynthetic reinforced slope for the purpose of recording seismic data at different elevation. It can be observed easily and clearly that the value of amplification factor is no way 
to be concluded into a simple number. We can observe exhaustively from Tables 1 to 3 without reaching any confident conclusion even considering the size of the earthquakes, epicenter locations, and the relationship between the various geological formations.

Table 1. Three recorded axial maximum seismic acceleration data at top portion (unit: $\mathrm{cm} / \mathrm{sec}^{2}$ )

\begin{tabular}{ccccc}
\hline \multicolumn{5}{c}{$\begin{array}{c}\text { At top portion of the geosynthetic reinforced slope } \\
\text { (Instrument Number 1316) }\end{array}$} \\
\hline Date & $\begin{array}{c}\text { a-axis } \\
\text { (Vertical) }\end{array}$ & $\begin{array}{c}\text { b-axis } \\
\text { (Transvrse) }\end{array}$ & $\begin{array}{c}\text { c-axis } \\
\text { (Longitudinal) }\end{array}$ & $\begin{array}{c}\text { Amplification } \\
\text { factor }\end{array}$ \\
\hline 20131031 & 0.239 & 0.658 & 19.918 & 1.854 \\
\hline 20131108 & 0.299 & 0.06 & 1.196 & 1.234 \\
\hline 20131116 & 0.299 & 0.179 & 0.957 & 1.308 \\
\hline 20131222 & 1.316 & 1.973 & 1.914 & 2.287 \\
\hline 20140109 & 0.12 & 0 & 0.897 & 1.667 \\
\hline 20140114 & 0.538 & 1.017 & 2.512 & 1.909 \\
\hline 20140115 & 0.06 & 0.12 & 1.674 & 3.112 \\
\hline 20140121 & 0 & 0.359 & 0.957 & 2.002 \\
\hline 20140124 & 0.897 & 0.179 & 3.648 & 3.211 \\
\hline 20140222 & 2.512 & 18.717 & 20.93 & 2.258 \\
\hline 20140416 & 0.12 & 0.12 & 0.897 & 1.875 \\
\hline
\end{tabular}

Table 2. Three recorded axial maximum seismic acceleration data at middle portion (unit: $\mathrm{cm} / \mathrm{sec}^{2}$ )

At middle portion of the geosynthetic reinforced slope (Instrument Number 1314)

\begin{tabular}{ccccc}
\hline Date & a-axis & b-axis & c-axis & Amplification \\
& (Vertical) & (Transvrse) & (Longitudinal) & factor \\
\hline 20131031 & 0.06 & 0.299 & 14.655 & 1.364 \\
\hline 20131108 & 0.239 & 0.718 & 0.757 & 1.217 \\
\hline 20131116 & 0.179 & 0 & 0.718 & 0.95 \\
\hline 20131222 & 0.837 & 1.196 & 1.196 & 1.429 \\
\hline 20140109 & 0.12 & 0 & 0.538 & 1 \\
\hline 20140114 & 0.179 & 0.239 & 1.615 & 1.227 \\
\hline 20140115 & 0.06 & 0.239 & 1.017 & 1.890 \\
\hline 20140121 & 0.239 & 0.12 & 0.718 & 1.501 \\
\hline 20140124 & 0.359 & 0.299 & 1.674 & 1.474 \\
\hline 20140222 & 2.033 & 5.143 & 13.216 & 1.426 \\
\hline 20140416 & 0.12 & 0.06 & 0.598 & 1.25 \\
\hline
\end{tabular}

Table 3. Three recorded axial maximum seismic acceleration data at ground surface (unit: $\mathrm{cm} / \mathrm{sec}^{2}$ )

At ground surface of the geosynthetic reinforced slope (Instrument Number 1146)

\begin{tabular}{ccccc}
\hline Date & $\begin{array}{c}\text { a-axis } \\
\text { (Vertical) }\end{array}$ & $\begin{array}{c}\text { b-axis } \\
\text { (Transvrse) }\end{array}$ & $\begin{array}{c}\text { c-axis } \\
\text { (Longitudinal) }\end{array}$ & $\begin{array}{c}\text { Amplification } \\
\text { factor }\end{array}$ \\
\hline 20131031 & 1.854 & 0 & 10.587 & 1 \\
\hline 20131108 & 0.12 & 0.12 & 0.598 & 1 \\
\hline 20131116 & 0.239 & 0.179 & 0.718 & 1 \\
\hline 20131222 & 0.658 & 1.076 & 0.837 & 1 \\
\hline 20140109 & 0.06 & 0.12 & 0.538 & 1 \\
\hline 20140114 & 0.12 & 0.299 & 1.316 & 1 \\
\hline 20140115 & 0.12 & 0.06 & 0.538 & 1 \\
\hline 20140121 & 0.06 & 0 & 0.478 & 1 \\
\hline 20140124 & 0.239 & 0 & 1.136 & 1 \\
\hline 20140222 & 0.239 & 3.648 & 9.269 & 1 \\
\hline
\end{tabular}

\section{FEM NUMERICAL SIMULATION}

The PLAXIS finite element computer program is an appropriate geotechnical engineering software for the seismic simulation. PLAXIS computer program is able to analyze various soil and structure interaction problems, which would be the case of geosynthetic reinforcement. During the earthquake simulation process, the dynamic loading in the form of acceleration time history is applied along the bottom boundary of the model profile resulting to shear waves that propagates upwards.

The boundary conditions of the study geosynthetic reinforced slope are set to be fixed for the horizontal displacements on both the front side and the back side, which are generally also assumed to be absorbing boundaries. Additionally, both the vertical and horizontal displacements at the bottom boundary are set to be fixed where the dynamic acceleration time record is given for the seismic simulation of the study geosynthetic reinforced slope.

In this study, the profile of the geosynthetic reinforced slope is designed as three tires placing the geosynthetic reinforcement with tensile strength of $200 \mathrm{kN} / \mathrm{m}$. The model geometrical profile of the geosynthetic reinforced slope is shown in Figure 4.

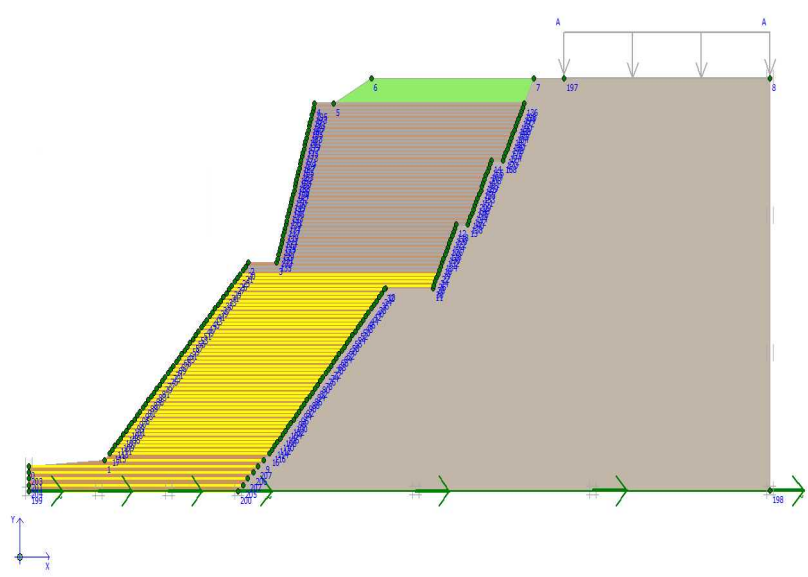

Fig. 4. Designed schematic cross-section for the seismic FEM simulation.

In the model, the height of the first tier (base tier) of the geosynthetic reinforced slope is $2.5 \mathrm{~m}$ with 6 layers of geosynthetic reinforcements, which elevation depth is designed as $0.5 \mathrm{~m}$. The height and the angle of the second tier (intermediate tier) of the geosynthetic reinforced slope is $15.5 \mathrm{~m}$ and $45^{\circ}$ with 51 layers of geosynthetic reinforcements, which elevation depth is designed as $0.3 \mathrm{~m}$. The height and the angle of the third tier (top tier) of the geosynthetic reinforced slope is $12.5 \mathrm{~m}$ and $73^{\circ}$ with 41 layers of geosynthetic reinforcements, which elevation depth is also designed as $0.3 \mathrm{~m}$. Additionally, on the top of the geosynthetic reinforced slope, there is a $2 \mathrm{~m}$ thick backfill material, which needs to be added cement material to mix before filling. All the material properties used in this study are list in Table 4. 
Table 4. The material properties for the PLAXIS simulation

\begin{tabular}{|c|c|c|c|}
\hline $\begin{array}{l}\text { Soil/ rock } \\
\text { Category }\end{array}$ & Backfill & Reinforcing zone & Residual \\
\hline$\gamma\left(\mathrm{kN} / \mathrm{m}^{3}\right)$ & 22 & 20 & 22 \\
\hline $\begin{array}{l}\gamma_{\text {sat }} \\
\left(\mathrm{kN} / \mathrm{m}^{3}\right)\end{array}$ & 22.5 & 21 & 23.5 \\
\hline$c\left(\mathrm{kN} / \mathrm{m}^{2}\right)$ & 7.5 & 8 & 17 \\
\hline$\Phi\left(^{\circ}\right)$ & 29 & 31 & -- \\
\hline$\Psi\left(^{\circ}\right)$ & 0 & 10 & -- \\
\hline $\mathrm{E}\left(\mathrm{kN} / \mathrm{m}^{2}\right)$ & 10000 & 40000 & -- \\
\hline v & 0.4 & 0.1 & - \\
\hline EA (kN/m) & -- & 4000 & -- \\
\hline
\end{tabular}

With the input data of the 20140222 earthquake, the maximum acceleration of the first tier (base tier) of the geosynthetic reinforced slope is $9.4 \mathrm{~cm} / \mathrm{sec}^{2}$ occurred at 37.92 seconds; the maximum acceleration of the second tier (intermediate tier) is $10.7 \mathrm{~cm} / \mathrm{sec}^{2}$ occurred at 38.4 seconds; the maximum acceleration of the third tier (top tier) is $21.5 \mathrm{~cm} / \mathrm{sec}^{2}$ occurred in 41.76 seconds. Figure 5 demonstrates the predicted acceleration variation, from the PLAXIS program, at the three different elevations of the study geosynthetic reinforced slope for the 20140222 earthquake.

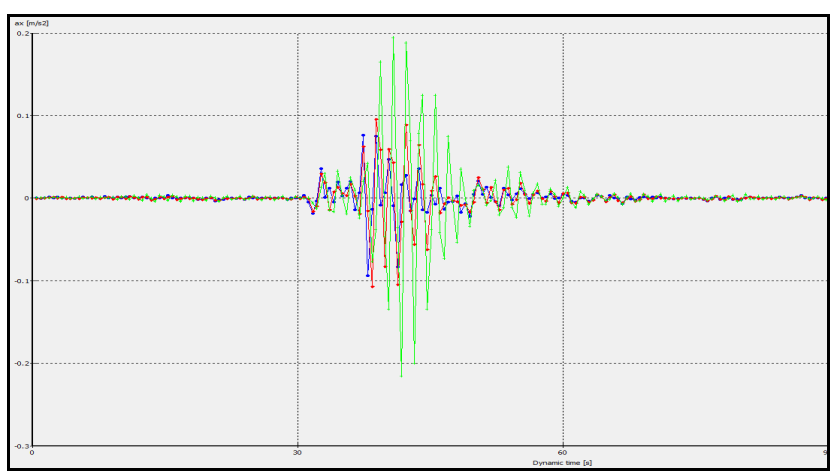

Fig. 5. Comparison of acceleration time histories at three different elevations by the 20140222 earthquake.

Employing the PLAXIS program to analyze the 20140222 earthquake with the acceleration time histories, the maximum acceleration at the third tier (top tier) compared to the maximum acceleration of the first tier (base tier) is 2.287 times; the maximum acceleration at the second tier (middle tier) compared to the maximum acceleration of the first tier (base tier) is 1.138 times. The simulation results of the maximum accelerations are summarized in Table 5.

Table 5. Maximum seismic accelerations obtained from PLAXIS simulation

\begin{tabular}{ccc}
\hline & $\begin{array}{c}\text { maximum } \\
\text { acceleration }\left(\mathrm{cm} / \mathrm{s}^{2}\right)\end{array}$ & $\begin{array}{c}\text { Amplification } \\
\text { factor }\end{array}$ \\
\hline $\begin{array}{c}\text { the third tier } \\
\text { (top tier) }\end{array}$ & 21.5 & 2.287 \\
\hline $\begin{array}{c}\text { The second tier } \\
\text { (intermediate tier) }\end{array}$ & 10.7 & 1.138 \\
\hline $\begin{array}{c}\text { the first tier } \\
\text { (base tier) }\end{array}$ & 9.4 & 1 \\
\hline
\end{tabular}

\section{CONCLUSIONS}

There are 11 reliable seismic data so far recorded at different elevations of the geosynthetic reinforced slope built in FoGuang University utilizing the new developed seismic sensing instruments, Palert. This paper documented the maximum acceleration values of at different elevations during earthquakes and found that the maximum acceleration relationship cannot be ended up to a number at all. It is concluded from the directly monitored seismic data that there is no specific value for the site amplification factor of geosynthetic reinforced slope for seismic response.

It is apparent that the acceleration at the top portion of the geosysthetic reinforced slope would be higher than those at middle portion and at the ground surface of the geosysthetic reinforced slope. This is the concept of site amplification effect under small to medium earthquakes as everybody has been acquainted with by now (Kramer, 1996). For instance, the recorded acceleration is $20.93 \mathrm{gal}$ at the top portion, $13.216 \mathrm{gal}$ at the middle portion, and $10.587 \mathrm{gal}$ at the ground surface of the geosysthetic reinforced slope on the longitudinal direction by the 20140222 earthquake.

The acceleration time histories of the geosynthetic reinforced slope can be simulated by PLAXIS computer program. The predicted maximum accelerations at different elevations have been compared with the recorded data of the seismic monitoring system. The amplification factor of the third tier (top tier) to the first tier (base tier) is 2.258 times from the monitoring record and is 2.287 times from the PLAXIS simulation for the 20140222 earthquake. The results are quite close and thus bring us the confidence of using numerical technique to work on seismic responses of geosynthetic reinforced slopes.

\section{ACKNOWLEDGEMENTS}

The authors would like to acknowledge the kind permission and generous help on the seismic monitoring system from the staffs of the General Affairs Office of the FoGoung University.

\section{REFERENCES}

1) Chao, S.J., (2010a): Performance Study of Geosynthetic Reinforced Soil Retaining Structures, Ground Improvement and Geosynthetics, Geotechnical Special Publication No. 207, 282-286.

2) Chao, S.J., Chou, N.S. and Liu, J.C. (2010b): Preliminary Dynamic Analysis for a High Steep Geosynthetic Reinforced Soil Retaining Structure: Fo-Guang University Case Study, Proceeding of the 1st International GSI-Asia Geosynthetics Conference, Taichung, Taiwan, 93-99.

3) Kramer, S.L. (1996): Geotechnical Earthquake Engineering, Prentice Hall, Upper Saddle River, New Jersey, USA, 653 pp.

4) Wu, Y.M. and Hiroo K. (2008): Development of an Earthquake Early Warning System Using Real-Time Strong Motion Signals, Sensors ISSN 1424-8220, MDPI, 1-9. 